fundus lesions we associate with toxicity of advancing age or senility. Diffuse depigmentary changes I have also observed in children, and have ascribed them to the autotoxæmia of gastroenteritis and such internal disturbances as infants are prone to. The nephritis is of the type which follows scarlet fever, and it is possible that the changes are produced by an infective element. It is also possible that fundus lesions are not uncommon in scarlatinal nephritis, but few of us have had the occasion to examine many cases of the kind. Syphilis has been suggested as the cause, but except in the two exceptional cases referred to above, the appearances of the fundus changes were not, to me, suggestive of syphilis. Sepsis, particularly oral sepsis, has also been suggested as a cause of the nephritis; but there is nothing in the fundus lesions, any more than in the epidemiological aspects of the disease, that gives any support to such a suggestion.

\title{
A CASE OF ETHMOIDAL INJURY ASSOCIATED WITH PAPILLEDEMA, ABDUCENS PALSY, AND OTHER OCULAR LESIONS
}

BY

Captain F. W. Watkyn-Thomas, B.C.Cantab., R.A.M.C. (T.C.) AND

Captain R. L. Scott, F.R.C.S.Edin., R.A.M.C. (T.C.) FROM A BASE HOSPITAL IN FRANCE.

PAPILLEDEMA and other affections of the eye have frequently been observed in cases of accessory sinus suppuration, more especially when the suppuration has been in the sphenoidal or posterior ethmoidal cells. The structural features have been fully described by Onodi, Loeb, and others.

The following case presents some points of interest :-

$\mathrm{N}$ - , a powerfully-built countryman, aged twenty-four, is a lance-corporal in a tunnelling company, with thirty months' service. There is no previous history of any ocular trouble except for a "black eye" (right) following a blow from a cricket ball three months previously. He is certain that he had quite recovered from this before he was wounded. On March 28, 1917, he was struck below the right eye by a fragment of 'shell; earlier in the day he had received a very slight bayonet wound in the right arm. There was no definite history of concussion, and he remembers being carried to the advanced dressing station.

The sight of the right eye has been dim from that time. The wound of the arm was excised, and the face wound, a small 
puncture on the lower and outer quadrant of the right orbit, was explored and drained. The orbital margin was found to be chipped, but no foreign body was discovered.

$\mathrm{He}$ arrived here late on April 9. On April 10 the wound of the arm was clean and granulating well. The face was asymmetrical, the angle of the mouth being lower on the right. (This is probably his normal state, as no weakness of the facial muscles has ever been detected.) There was a clean, nearly healed incision along the outer half of the right lower orbital margin. The right lower lid was a little swollen, but there was no swelling of the ocular conjunctiva, no proptosis, and no pain ; movements of the eye and pupil reflexes were normal. $\mathrm{He}$ could count fingers, but complained of dimness of vision. T. $976^{\circ}$ F.; P. 60 . In the morning he was quite well, but that evening complained of a slight headache.

On the morning of April 11 the headache had gone. T. 97\% F.; P. 52. In the afternoon he complained of intense and rapidly increasing pain in the right eye; the temperature remained the same, but the pulse rate fell to 48 , and he vomited.

All examination was impeded by the fact that he is always rather unresponsive and was then in great pain, pain which was apparently increased to an agonizing degree by any movement of the head. The lids were very swollen and there was chemosis of the ocular conjunctiva. There was no proptosis and no emphysema. There was definite tenderness over the inner canthus. Movements were sluggish in all directions. The pupil reacted to light, but slowly. The intra-ocular pressure was much raised. A very incomplete examination showed that the field was narrowed all around. Only with difficulty could he count fingers at $1 \mathrm{~m}$.

Ophthalmoscopic appearances.-Fundus hazy, vitreous hæmorrhages, much exudate, disc red, 3D. of swelling, no retinal hæmorrhages. Vessels, where visible, engorged. Left eye normal.

Nose and nasopharynx.-Clear, no pus seen, nothing abnormal found.

C.N.S.-Cranial motor nerves appeared to be intact, except for the sluggish pupil reflex and the poor movements of the right eye. No anæsthesia over area of the 5th nerve. Abdominal reflexes equal. Natural knee jerks; cremasteric reflexes equal. Plantar response flexor. No ankle clonus, no Kernig's sign, no tache cérebrale, no retraction of head or abdomen.

Skiagrams by Captain A. J. H. Iles demonstrated a small fragment of metal well forward, probably in the ethmoid labyrinth. Patient slept soundly after $\frac{1}{4}$ gr. morphia hypodermically, with aspirin, gr. xv, and phenacetin, gr. v, by mouth.

Operation April 12.-The intensity of the symptoms, the small size of the fragment, and the absence of discharge were all against 
any intranasal approach, which, also, would not have permitted exploration of the orbit. Guisez's route for the open ethmoid operation, again, would have given poor access to the orbit, and the same is true of the Killian ${ }^{1}$ method, although it gives an admirable exposure of the ethmoid gallery. Accordingly we decided on St Clair Thomson's modification of Moure's operation', which gives free exposure and trifling deformity. The nose was packed

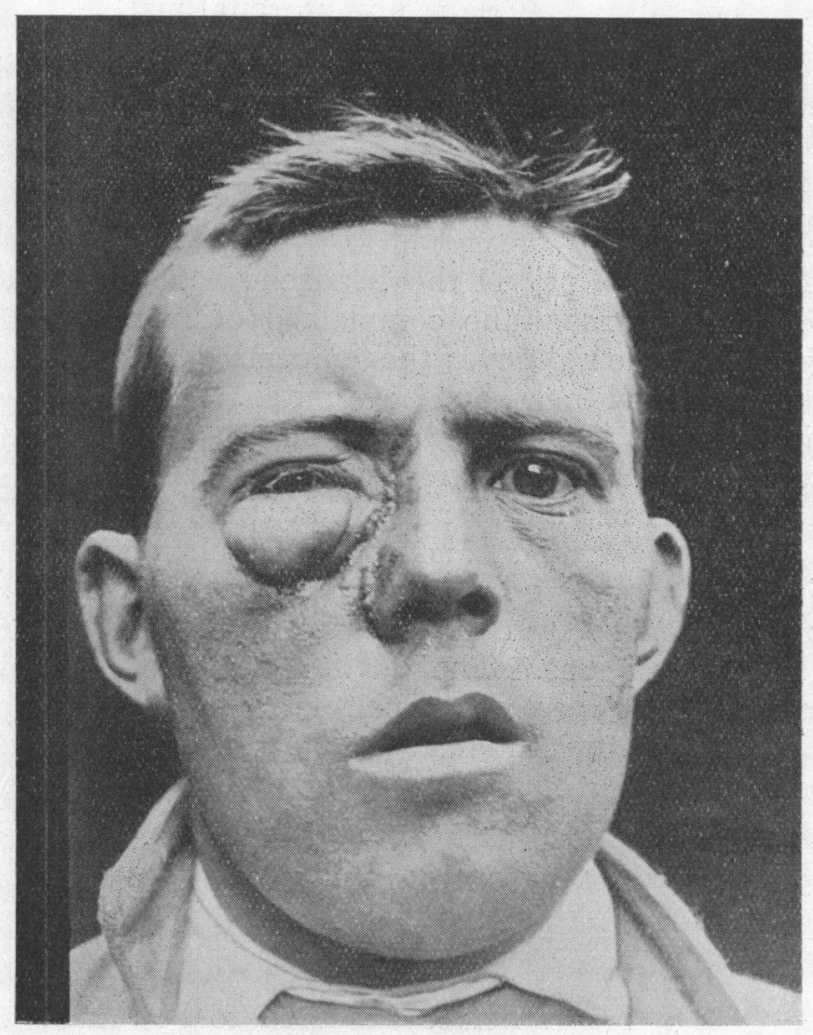

for 20 minutes with wool soaked in 10 per cent. cocain and $1 / 1000$ adrenalin, equal parts. After $\frac{1}{4}$ gr. morphia with $1 / 100$ gr. atropin, Captain M. W. Talbot gave chloroform by Junker's inhaler. Nasopharynx was packed with a sponge.

The old orbital incision was prolonged to meet the lateral nasal incision, which was made in the ordinary way, except that the lobule was not detached. The flap was turned back and the infraorbital nerve and lacrymal sac were retracted. The lower chisel cut was made higher into the vestibule than usual, as it was only the orbitoethmoidal region we wished to explore. When the supero-internal 
angle of the maxilla had been removed the fragment could not be found (a skiagram taken since has shown that it fell into the antrum probably through the chiselling). The ethmoid gallery was found to be considerably damaged; the bone was splintered as far back as the posterior cells, and the mucosa was engorged and odematous. The orbito-nasal wall was shattered. No pus was found. All loose bone and damaged mucosa were removed with Hartmann's forceps and Cordes's punch. The orbit was cautiously explored but no pus

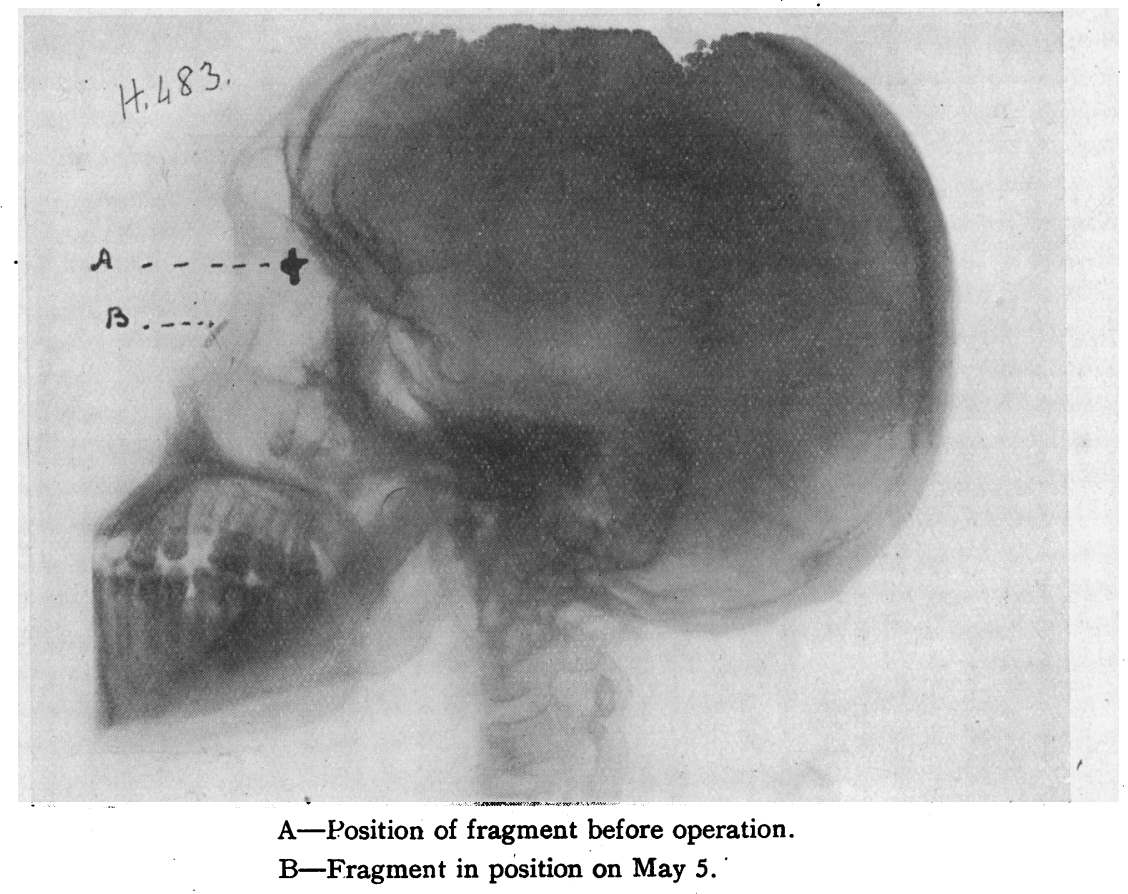

was found there, although the orbital connective tissue was very œdematous. For more efficient drainage we thought it advisable to sacrifice the upper part of the lateral nasal wall, which was already fractured by the chisel cuts. This was done with very little hæmorrhage. The flap was sutured with fine gut and the cavity packed with gauze ribbon soaked in $1 / 10$ bismuth in paraffin. When. he recovered from the anæsthetic, patient was quite free from pain. He slept well that night; P. 72 ; T. $100^{\circ}-4^{\circ} \mathrm{F}$. On April 13 the lids and conjunctiva were very swollen but the pupil reacted briskly. The plugs were removed, without any hæmorrhage, on April 14 and 15. Stitches taken out on April 19. The patient could now see quite clearly when the lids were drawn back but complained of "seeing double." On April 20 the swelling of the lids had diminished enough for a complete examination. The swelling 
of the disc was now only $1.5 \mathrm{D}$. as against $3 \mathrm{D}$. on April 11 . There was homonymous diplopia due to paralysis of the external rectus. The exudate had diminished and a vitreous hæmorrhage could be seen. He got up on April 21. On April 26 the diplopia was less marked and the swelling of the disc was only $0.75 \mathrm{D}$. On May 5 the edges of the disc were much clearer. When marked for England on May 8 the vision was R. 6/24 and L. 6/5.

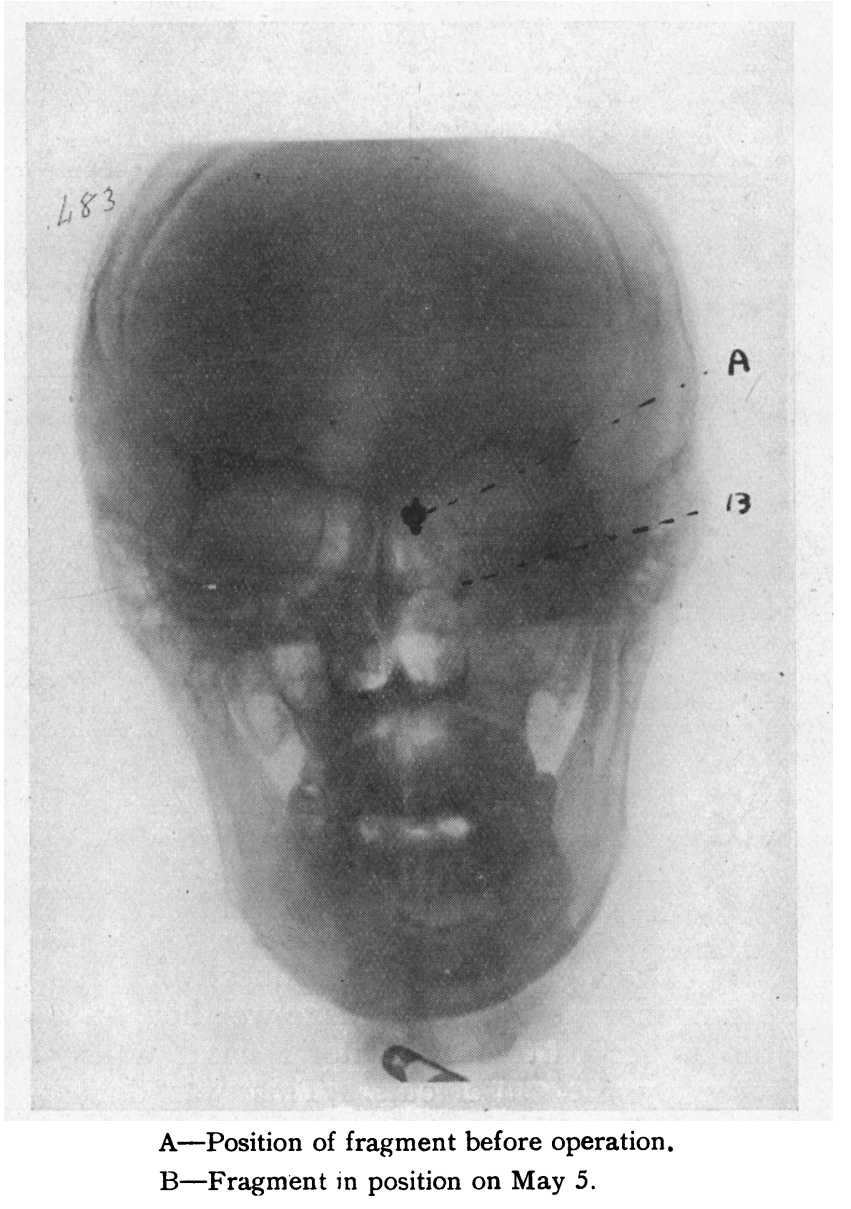

Skiagrams now showed that the fragment was quite superficial, but we thought that removal should be deferred until healing was more complete. When sent to England on May 12, there was no anæsthesia over the flap or of the upper lid; the lower lid was still œdematous. This seems to occur frequently after resection of the maxilla, and is possibly due to division of lymphatics by the transverse incision. There was very little epiphora or lacrymation. 
The vision of the right eye was $6 / 24$ and the weakness of the external rectus was much less.

There are several interesting points in the case :-

(1) The sudden onset of intense pain, which was probably due to the increase of tension.

(2) The association of greatly increased tension with papillitis.

(3) The paralysis of the external rectus.

Several cases of external rectus palsy and papillitis in association with accessory sinus suppuration have been described. Ewing and Sluder ${ }^{3}$, in a paper on this complex, attribute the paresis to the relation of the abducens, which lies lowest in the sphenoidal fissure, to the ethmoidal cells.

It is possible that the increased tension was produced by the pressure of the odematous orbital tissue on the ophthalmic veins.

\title{
REFERENCES
}

I. Killian.-Accessory Sinuses 1913, p. 304 .

2. St Clair Thomson. - Lancet, I916.

3. Ewing and Sluder. -Ophthalmoscope, 1915, Vol. XIII, p. 469.

\section{PROTECTION OF THE EYE IN WARFARE*}

\section{BY}

\author{
R. R. CRUise, C.V.O., \\ CAPTAIN R.A.M.C. (T.).
}

WHEREVER the question of body armour arises, the two discordant factors of efficacy and practicability have to be faced.

The steel helmet was the first great and effective compromise between these two factors, and even then it required a rigid discipline to enforce its usage upon a reckless and reluctant soldiery.

The measure of protection against injuries to the head afforded by the steel helmet will, it is hoped, find a parallel in the case of the eye, in the visor which I have designed, and which the War Office has accepted and adopted, and which is now on its trial on an extensive scale.

But before describing the visor, it is necessary to consider the types of injury to which eyes are liable in warfare.

From the point of view of protection, eye injuries may be divided into two classes :-
(a) preventible; (b) non-preventible.

*Communicated to the 1917 Congress of the Ophthalmological Society of the United Kingdom. The full communication will be published in the Society's Transactions. 